\title{
HUBUNGAN TEMPAT SEKOLAH DENGAN PENGETAHUAN TENTANG KESEHATAN REPRODUKSI REMAJA PADA PELAJAR SMA DI KABUPATEN LEBAK
}

\begin{abstract}
Suhartini*
Abstrak

Diperkirakan seperlima dari penduduk dunia adalah remaja.Di negara wilayah Asia Tenggara proporsi penduduk remaja mencapai 18-25 \%.Di Indonesia pengertian remaja adalah mereka yang berusia 10 hingga 19 tahun dan belum menikah. Data tentang pengetahuan tentang kesehatan reproduksi remaja di propinsi Banten dapat diungkapkan dari hasil penelitian Farihah (2002) pengetahuan tentang kesehatan reproduksi remaja di tiga SMUN di kota Serang ditemukan bahwa 3.3\% berpengetahuan kurang baik, $21.3 \%$ berpengetahuan sedang dan $75 \%$ berpengetahuan baik. Pengetahuan remaja tentang kesehatan reproduksi remaja di kabupaten Lebak provinsi Banten belum diketahuiPenelitian ini bertujuan untuk mengetahui hubungan tempat sekolah dengan pengetahuan tentang kesehatan reproduksi remaja pada pelajar SMA.

Penelitian ini adalah penelitian kuantitatif dengan menggunakan desain studi crossectional. Data yang diambil adalah data primer dengan menggunakan kuesioner dilakukan pada bulan April sampai dengan Mei 2008.

Hasil penelitian mendapatkanproporsi remaja SMA di kabupatenLebakyang berpengetahuan kurang baik dalam hal kesehatan reproduksi remaja(65.7\%). Hasil uji statistik menunjukkan ada hubungan antara tempat sekolah dengan pengetahuan tentang kesehatan reproduksi remaja OR 4.510 (CI 2.660-7.647) artinya pelajar SMA negeri memiliki pengetahuan yang lebih baik tentang kesehatan reproduksi remaja 4.5 kali dibanding pelajar SMA di pondok pesantren.

Untuk itu disarankan agar Sekolah Menengah Atas di kabupaten Lebak dapat membekali pelajar dengan pengetahuan tentang Kesehatan Reproduksi Remaja (KRR) agar mereka memiliki pengetahuan yang benar tentang sistem, fungsi dan proses reproduksi manusia.
\end{abstract}

Kata Kunci : Tempat sekolah, pengetahuan tentang kesehatan reproduksi remaja, pelajar SMA, Cross Sectional

* Poltekkes Kemenkes Banten 


\title{
Correlation between Place of School and the awareness of teenager reproduction health among high school students in Lebakdistric, province Banten2008.
}

\author{
Suhartini*
}

\begin{abstract}
It is estimated that one-fifth of world population is teenager. In South East Asia, teenager proportion reaches to 18-25\%. Indonesian the meaning of teenagers those who reaches 10 to 19 years of age and unmarried. The data about teenagersHealth Reproduction in can be exressed from the Farihah research (2002). She indicates that the knowledge of teenager on health reproduction in three senior high school in Serang, 3,3\% are unfavorable knowledge, 21,3\% are knowledge, and $75 \%$ are well knowledge. The adolescent knowledge about teenager reproduction healh in.LebakBantenprovince has not been known yet.The study aims at the correlation between place of school and the awareness of teenager reproduction health among high school students

The study is quantitative research using crossectionalstudy design carried out from April to May 2008.

The result proportion of high school students having a low awareness on teenager reproduction health is $65.7 \%$. The statistic test result shows an imminent correlation between place of school and the awareness of teenager reproduction health OR 4.510 (CI 2.660 7.647) in meaning that state high school students in Lebak has 4.5 value better awareness on the issue of teenager reproduction health compared to boarding high school students.

Therefore it is study suggested to senior high school in Lebak can aply student with knowledge about teenager health reproduction in order that they have the right knowledge about the system, the fungction and the process of human reproduction.
\end{abstract}

Key words : Place of high school, awerness of teenager reproductin health, high school students, Cross Sectional

\section{Pendahuluan}

Kesehatan reproduksi remaja penting karena masa ini terjadi transisi antara masa kanak-kanak dengan dewasa dan relatif belum mencapai tahap kematangan mental dan sosial, sehingga mereka harus menghadapi tekanan-tekanan emosi dan sosial yang saling bertentangan. Banyak sekali life events yang akan terjadi yang tidak saja akan menentukan kehidupan masa dewasa tetapi juga kualitas hidup generasi berikutnya, sehingga menempatkan masa ini sebagai masa kritis.

Dari data Badan Pusat Statistik (BPS) kabupaten Lebak diketahui penduduk wanita umur 10 tahun keatas yang pernah kawin menurut umur perkawinan pertama cukup mengejutkan karena 18,30\% 
menikah pada usia $<15$ tahun, 15,39 $\%$ menikah pada usia 16 tahun, 34,2\% menikah pada usia 17-18 tahun, $30.11 \%$ menikah usia 19-24 tahun, dan hanya $1,78 \%$ yang menikah diatas 25 tahun.(SUSENAS 2005, Lebak dalam angka, BPS Lebak tahun 2006).

Hasil penilaian cepat terhadap pelayanan dan persepsi masyarakat tentang kesehatan maternal dan neonatal di kabupaten Lebak, diketahui bahwa tidak ditemukan data mengenai kesehatan remaja (15-19 tahun ) di kabupaten Lebak, dari hasil wawancara mendalam diketahui karena tidak ada program untuk menjangkau remaja (Depkes RI-UNICEF hal 5, 2006).

Memperhatikan kondisi dan permasalahan yang ada di kabupaten Lebak, pada dasarnya masalah ini muncul disebabkan kurangnya pengetahuan, sikap dan perilaku remaja terhadap kesehatannya, serta belum adanya penelitian tentang pengetahuan kesehatan reproduksi remaja pada anak SMA di kabupaten Lebak, mendorong penulis untuk melakukan penelitian ini.

Penelitian ini bertujuan untuk mengetahui hubungan antara tempat sekolah dengan pengetahuan tentang kesehatan reproduksi remaja pada pelajar SMA di kabupaten Lebak Faktor - faktor yang diuji meliputi umur, umur menarche / mimpi basah, jenis kelamin, pendidikan ibu, pemberian materi kesehatan reproduksi di sekolah, sumber informasi utama kesehatan reproduksi, serta akses informasi kesehatan reproduksi remaja.

\section{Metode Penelitian}

Penelitian ini dilakukan secara kuantitatif dengan menggunakan data primer melalui rancangan studi potong lintang (cross sectional), untuk mengetahui hubungan tempat sekolah dengan pengetahun tentang kesehatan reproduksi remaja pada pelajar SMA.

Penelitian ini dilaksanakan di Kabupaten Lebak pada bulan April Mei 2008. Populasi target penelitian ini adalah seluruh remaja SLTA negeri maupun swasta yang ada di kabupaten Lebak.Untuk memperoleh besar sampel digunakan rumus perhitungan sampel diperoleh sampel sebesar 442 orang, untuk menghindari kemungkinan dropout dan lainnya sampel dibulatkan menjadi 460 orang.Tehnik pengambilan sampel dilaksanakan dua tahap, tahap pertama dilakukan pengambilan sampel secara proporsional selanjutnya untuk sampel di sekolah dikumpulkan dengan menggunakan Sistimatik random sampling. 
Hasil Penelitian

\section{Analisis Univariat}

Tabel 1

Distribusi responden berdasarkan tempat sekolahdi kabupaten Lebak tahun 2008

\begin{tabular}{clcc}
\hline NO & Tempat Sekolah & Frek & $\%$ \\
\hline 1 & SLTA negeri & 325 & 70.7 \\
2 & SLTA di pondok & 135 & 29.3 \\
& pesantren & & \\
\hline \multicolumn{2}{c}{ Jumlah } & 460 & 100 \\
\hline
\end{tabular}

Pada tabel 1 menunjukkan

bahwa sebagian besar responden

(70,7\%) bersekolah di SLTA negeri.

Tabel .2

Distribusi responden berdasarkan pengetahuan tentang Kespro remaja di kabupaten Lebak tahun 2008

\begin{tabular}{lllc}
\hline No & $\begin{array}{l}\text { Pengetahuan ttg } \\
\text { Kespro Remaja }\end{array}$ & Frek & $\%$ \\
\hline 1 & Baik & 137 & 34.3 \\
2 & Kurang baik & 302 & 65.7 \\
\hline & Jumlah & 460 & 100 \\
\hline & Pada tabel & 2 & menunjukkan
\end{tabular}
bahwa sebagian besar responden memiliki pengetahuan yang kurang baik tentang kesehatan reproduksi remaja(65.7\%).

Tabel3

Distribusi responden menurut umur di kabupaten Lebak tahun 2008

\begin{tabular}{ccccc}
\hline $\begin{array}{c}\text { Vari } \\
\text { abel }\end{array}$ & Mean & $\begin{array}{c}\text { Median/ } \\
\text { Mode }\end{array}$ & SD & $\begin{array}{c}\text { Min- } \\
\text { Maks }\end{array}$ \\
\hline Umur & 16.75 & $17 / 17$ & 0.725 & $15-19$ \\
\hline & Pada tabel 3 & memperlihatkan
\end{tabular}
rata-rata umur responden 16.75 tahun dengan median 17 tahun dan mode 17 tahun , serta standar deviasi 0,725.Umur terendah 15 tahun dan tertinggi 19 tahun.
Tabel 4

Distribusi responden menurut umur menarche dan umur mimpibasah di kabupaten Lebak tahun 2008

\begin{tabular}{lcccc}
\hline $\begin{array}{c}\text { Varia- } \\
\text { bel }\end{array}$ & Mean & Median & Mode & SD \\
\hline $\begin{array}{l}\text { Umur } \\
\text { menar } \\
\text { che }\end{array}$ & 13.25 & 13 & 13 & 1.251 \\
$\begin{array}{l}\text { Umur } \\
\text { mimpi }\end{array}$ & 13.75 & 14 & 15 & 1.689 \\
basah & & & & \\
$\begin{array}{l}\text { Umur } \\
\text { menar } \\
\text { chel } \\
\text { mimpi }\end{array}$ & 13.46 & 13 & 13 & 1.467 \\
basah & & & & \\
\end{tabular}

Pada tabel 4 memperlihatkan bahwa rata-rata umur menarche 13.25 tahun dengan median 13 tahun dan mode 13 tahun serta umur terendah mentruasi 10 tahun dan tertinggi 16 ,Sedangkan rata-rata umur mimpi basah 13.75 tahun dengan median 14 tahun , mode 15 tahun. Umur terendah 10 tahun dan tertinggi 17 tahun

Tabel 5.

Distribusi respoden berdasarkan jenis kelamindi kabupaten Lebak tahun2008

\begin{tabular}{|c|c|c|}
\hline Jenis kelamin & Frek & $\%$ \\
\hline Laki-laki & 187 & 40.7 \\
\hline Perempuan & 273 & 59.3 \\
\hline Jumlah & 460 & 100 \\
\hline
\end{tabular}

bahwa respoden yang berjenis kelamin perempuan proporsinya sedikit lebih tinggi ( $59,3 \%$ ), dibanding responden laki-laki (40.7\%). 
Tabel 6

Distribusi responden berdasarkan tempat tinggal

di kabupaten Lebak tahun 2008

\begin{tabular}{lcc}
\hline Tempat tinggal & Frek & $\%$ \\
\hline Bersama orang tua & 303 & 65.9 \\
Tidak bersama orang tua & 157 & 34.1 \\
\hline \multicolumn{1}{c}{ Jumlah } & 460 & 100
\end{tabular}

Pada tabel 6 memperlihatkan

bahwa sebagian besar responden

tinggal bersama orang tua (65.9\%),

dan sebagian kecil lainnya tidak

tinggal bersama dengan orang tua $(34.1 \%)$.

Tabel 7

Distribusi responden berdasarkan pendidikan ibu di kabupaten Lebak tahun 2008

\begin{tabular}{|c|c|c|}
\hline Katagori & \multicolumn{2}{|c|}{ Pendidikan Ibu } \\
\hline Pendidikan & Frek & $\%$ \\
\hline Tinggi & 228 & 49,6 \\
\hline Rendah & 232 & 50.4 \\
\hline Jumlah & 460 & 100 \\
\hline
\end{tabular}

bahwa distribusi responden berdasarkan pendidikan ibu proporsinya hampir sama antara pendidikanrendah $(50.4 \%)$ dan pendidikantinggi (49.6\%).

Tabel 8

Distribusi responden berdasarkan Pemberian materi KRRdi sekolah kabupaten Lebak tahun 2008

\begin{tabular}{ccc}
\hline Katagori & \multicolumn{2}{c}{ Materi KRR } \\
\cline { 2 - 3 } Informasi & Frek & $\%$ \\
\hline Pernah diberikan & 369 & 80.2 \\
Tdk permah diberikan & 91 & 19.8 \\
\hline Jumlah & 460 & 100 \\
\hline Pada tabel & 8 & menunjukkan
\end{tabular}

bahwa sebagian besar responden diberikan materi kesehatan reproduksiremaja disekolahnya $(80.2 \%)$,
Tabel .9

Distribusi responden berdasarkan sumber informasi di kabupaten Lebak tahun 2008

\begin{tabular}{lcc}
\hline $\begin{array}{l}\text { Sumber Informasi utama } \\
\text { kespro remaja }\end{array}$ & Frek & $\%$ \\
\hline $\begin{array}{l}\text { Orang tua dan atau Guru } \\
\text { Selain orang tua dan atau }\end{array}$ & 398 & 86.5 \\
guru & 62 & 13.5 \\
\hline \multicolumn{1}{c}{ Jumlah } & 460 & 100 \\
\hline
\end{tabular}

Pada tabel 9 menunjukkan bahwa sebagian besar responden menyatakan orang tua dan atau guru merupakan sumber informasi utama kesehatan reproduksi remaja $(86.5 \%)$.

Tabel 10

Distribusi responden berdasarkan akses informasi KRR melalui media di kabupaten Lebak tahun 2008

\begin{tabular}{lcc}
\hline $\begin{array}{l}\text { Akses informasi } \\
\text { KRR }\end{array}$ & Frek & $\%$ \\
\hline Media elektronik & 237 & 51.5 \\
Media cetak & 223 & 48.5 \\
\hline \multicolumn{1}{c}{ Jumlah } & 460 & 100 \\
\hline \multicolumn{1}{c}{ Pada tabel } & 10 & menunjukkan
\end{tabular}

bahwa responden yang memperoleh informasi kesehatan reproduksi remaja melalui media elektronik proporsinya hampir sama dengan yang mengakses melalui media cetak masing-masing $51.5 \%$ dan $48,5 \%$.

\section{Analisis bivariat}

Uji statistik yang digunakan untuk melihat hubungan variabel independen utama dan kovariat dengan variabel dependen menggunakan uji kai kuadrat (chi square)

\section{Hubungan tempat sekolah dengan pengetahuan tentang kesehatan}


reproduksi remaja di kabupaten Lebak tahun 2008

Hasil uji statistik kai kuadrat (Chi Square) pada $\alpha=0.05$ diperoleh p.value $=0,000 \quad(\mathrm{p}<0.05)$ yang berarti bahwa secara statistik ada hubungan yang bermakna antara tempat sekolah dengan pengetahuan tentang kesehatan reproduksi remaja. Dari hasil analisis juga diperoleh nilai $\mathrm{OR}=3.956$ artinya pelajar SMA negeri mempunyai peluang 3.9 kali lebih tinggi untuk memiliki pengetahuan yang baik tentang kesehatan reproduksi remaja dibandingkan pelajar SMA di pondok pesantren.

\section{Hubungan umur dengan pengetahuan tentang kesehatan reproduksi remajadi kabupaten Lebak tahun 2008}

Dari hasil uji statistik diperoleh P.value $<0.05$ yaitu 0.003 berarti ada hubungan bermakna antara umur dan pengetahuan tentang kesehatan reproduksi remaja. Dari hasil analisis juga diperoleh nilai $\mathrm{OR}=2.937$, artinya responden yang berusia $<17$ tahun berpeluang 2.9 kali lebih tinggi untuk memiliki pengetahuan yang baik tentang kesehatan reproduksi remaja dibandingkan responden yang berusia dibawah $\geq 17$ tahun.
3. Hubungan umur menarche /mimpi basah dengan pengetahuan tentang kesehatan reproduksi remaja di kabupaten Lebak tahun 2008

Pengkatagorian umur menarche/mimpi basah dilakukan berdasarkan median umur menarche/mimpi basah (median =13) dan dikelompokkan menjadi dua kelompok $(<13$ tahun dan $\geq 13$ tahun). Hasil analisis terlihat pada tabel 5.13 yang mengemukakan bahwa responden yang berpengetahuan kurang baik proporsinya sedikit lebih tinggi pada responden berumur lebih dari 13 tahun (66.8\%), sedangkan pada usia $<13$ tahun tidak jauh berbera (64.5\%). Dari hasil uji statistik diperoleh $\mathrm{p}$ value $>0.05$ yaitu $\mathrm{p}=0.676$ yang berarti tidak ada hubungan bermakna antara umur menarche/mimpi basah dengan pengetahuan tentang kesehatan reproduksi remaja

\section{Hubungan jenis kelamin dengan pengetahuan tentang kesehatan reproduksi remaja di kabupaten Lebak tahun 2008}

Hasil uji statistik kai kuadrat (Chi Square) pada $\alpha=0.05$ diperoleh P.value $=0,122 \quad(p>0.05)$ yang berarti bahwa secara statistik tidak ada hubungan yang bermakna antara jenis kelamin responden dengan pengetahuan tentang kesehatan reproduksi remaja. 
5. Hubungan tempat tinggal dengan pengetahuan tentang kesehatan reproduksi remajadi kabupaten Lebak tahun 2008

Hasil uji statistik kai kuadrat (Chi Square) pada $\alpha=0.05$ diperoleh p.value $=0,000(\mathrm{p}<0.05)$ yang berarti bahwa secara statistik ada hubungan yang bermakna antara tempat tinggal responden dengan pengetahuan tentang kesehatan reproduksi remaja. Dari hasil analisis juga diperoleh nilai $\mathrm{OR}=3.096$, artinya responden yang tinggal bersama orang tua mempunyai peluang 3 kali lebih tinggi untuk memiliki pengetahuan yang baik tentang kesehatan reproduksi remaja dibandingkan responden yang tidak tinggal bersama orang tua

\section{Hubungan pendidikan ibu dengan pengetahuan tentang kesehatan reproduksi remaja di kabupaten Lebak tahun 2008}

Hasil uji statistik kai kuadrat (Chi Square) pada $\alpha=0.05$ diperoleh p.value $=0,028 \quad(\mathrm{p}<0.05)$ yang berarti bahwa secara statistik ada hubungan yang bermakna antara pendidikan ibu dengan pengetahuan tentang kesehatan reproduksi remaja. Dari hasil analisis juga diperoleh nilai $\mathrm{OR}=1,537$, artinya responden dengan pendidikan ibu tinggi mempunyai peluang 1,5 kali lebih untuk memiliki pengetahuan yang baik tentang kesehatan reproduksi remaja dibandingkan responden dengan pendidikan ibu rendah

7. Hubungan materi KRR dengan pengetahuan tentang kesehatan reproduksi remaja di kabupaten Lebak tahun 2008

Hasil uji statistik kai kuadrat (Chi Square) pada $\alpha=0.05$ diperoleh $\mathrm{p}$. value $=0,000 \quad(\mathrm{p}<0.05)$ yang berarti bahwa secara statistik ada hubungan yang bermakna antara perolehan materi KRR dengan pengetahuan tentang kesehatan reproduksi remaja. Dari hasil analisis juga diperoleh nilai $\mathrm{OR}=3.206$ artinya responden yang pernah memperoleh materi KRR cukup di sekolah mempunyai peluang $3.2 \mathrm{kali}$ lebih tinggi untuk memiliki pengetahuan yang baik tentang kesehatan reproduksi remaja dibandingkan mereka yang kurang memperoleh materi kesehatan reproduksi di sekolah.

Salah satufaktor yang sering dianggap menurunkan motivasi siswa motivasi untuk belajar adalah materi pelajaran dan guru. Mengenai materi pembelajaran yang sering dikeluhkan adalah membosankan, terlalu sulit dan tidak bermanfaat (Sarwono , 2007 :125).

8. Hubungan sumber informasi utama KRR dengan pengetahuan 
tentang kesehatan reproduksi remaja di kabupaten Lebak tahun 2008

Hasil uji statistikkai kuadrat (Chi Square) pada $\alpha=0.05$ diperoleh p.value $=0,275 \quad(p>0.05)$ yang berarti bahwa secara statistik tidak ada hubungan yang bermakna antara sumber informasi kesehatan reproduksi dengan pengetahuan tentang kesehatan reproduksi remaja

\section{Hubungan akses informasi KRR dengan pengetahuan tentang kesehatan reproduksi remaja di kabupaten Lebak tahun 2008}

Hasil uji statistik kai kuadrat (Chi Square) pada $\alpha=0.05$ diperoleh P.value $=1.000 \quad(p>0.05)$ yang berarti bahwa secara statistik tidak ada hubungan yang bermakna antara media informasi kesehatan reproduksi dengan pengetahuan tentang kesehatan reproduksi remaja.

\section{Analisis Multivariat}

Analisis multivariat bertujuan untuk melihat hubungan variabel independen (tempat sekolah) dengan dengan pengetahuan tentang kesehatan reproduksi remaja, hubungan beberapa variabel kovariat (umur, umur menarche pertama/mimpi basah, jenis kelamin, tempat tinggal, pendidikan ibu, materi kesehatan reproduksi, sumber informasi utama kesehatan reproduksi, akses informasi kesehatan reproduksi melalui media), Analisis yang digunakan adalah analisis logistic ganda dengan model factor risiko. Model yang digunakan adalah model yang parsimonius yaitu model yang valid, presisinya baik dan sederhana . Langkah-langkah yang dilakukan untuk memperoleh model yang parsimonius tersebut adalah pembuatan Hierarchiacally Well Formulated Model (HWF Model), melakukan Hierarchiacally Backward

\section{Elimination}

Berdasarkan model akhir yang dianggap paling baik diketahui bahwa variable pendidikan ibu dan jenis kelamin merupakan variable confounding dan harus tetap berada dalam model.

Hasil model akhir analisis multivariat, diketahui bahwa variable tempat sekolah berhubungan dengan pengetahuan tentang kesehatan reproduksi remaja setelah dikontrol dengan variable pendidikan ibu dan jenis kelamin dengan nilai odds rasio (OR) sebesar 4.510 (CI.2.660-7.647) artinya remaja bersekolah di SMA negeri mempunyai kecendrungan untuk memiliki pengetahuan tentang kesehatan reproduksi remaja yang baik 4.5 kali dibandingkan remaja yang bersekolah di SMA swasta di pondok 
pesantren setelah dikontrol dengan variable pendidikan ibu, dan jenis kelamin.

\section{Pembahasan}

\section{Tempat Sekolah}

Dari Hasil penelitian di dua tempat sekolah yang berbeda yaitu SMA negeri dan pondok pesantren diketahui pula bahwa rata-rata nilai SMA negeri dan pondok pesantren (64.88), median 65 nilai tertinggi 86 dan terendah 18 . Responden yang memiliki pengetahuan yang kurang baik proporsinya lebih tinggi pada mereka yang bersekolah di SMAdi pondok pesantren $(84,4 \%)$ dibandingkan yang bersekolah di SMA negeri $(57.8 \%)$.

\section{Menurut Havighurst (1961:5)} sekolah mempunyai peranan atau tanggung jawab yang penting dalam membantu para siswa mencapai tugas perkembangannya. Sehubungan dengan hal ini, sekolah seyogyanya berupaya menciptakan iklim yang kondusif, atau kondisi yang dapat memfasilitasi siswa untuk mencapai tugas perkembangannya (Yusuf, 2005 :55).

Pengaruh sekolah tentunya diharapkan positif terhadap perkembangan jiwa remaja, karena sekolah adalah lembaga pendidikan . Sebagai lembaga pendidikan sebagaimana halnya dengan keluarga sekolah juga mengajarkan nilai dan norma yang berlaku di masyarakat.

Mengenai peranan sekolah dalam mengembangkan kepribadian anak Hurlock (1986:322) dalam Yusuf (2005, : 54) mengemukakan bahwa sekolah merupakan faktor penentu bagi perkembangan kepribadian anak baik dalam cara berpikir, bertindak maupun berperilaku.

\section{Pengetahuan tentang KRR}

Dari hasil penelitian ini didapatkan bahwa prevalensi remaja SMA yang berpengetahuan kurang baik dalam hal kesehatan reproduksi remaja di kabupaten Lebak proporsinya lebih besar $(65.7 \%)$, sedangkan yang berpengetahuan baik hanya (34.3\%). Hal ini terjadi dimungkinkan karena masih kurangnya peran dan tanggung jawab sekolah dalam menyampaikan materi yang berkaitan dengan kesehatan reproduksi remaja di sekolahnya masing-masing.

Sebagaimana diketahui bahwa, intelegensia pada masa remaja menggambarkan bahwa remaja mampu berpikir abstrak, senang memberikan kritik, ingin mengetahui hal-hal baru, sehingga muncul perilaku ingin mencoba-coba. Perilaku ingin mencoba hal-hal baru merupakan hal 
yang sangat penting bagi kesehatan reproduksi dalam masa remaja

Ciri-ciri perubahan ini penting sekali karena dengan benar-benar memahami maka penanganan masalah dapat dilakukan dengan lebih baik. Ciri-ciri perubahan ini, terutama perilaku ingin mencoba-coba hal-hal baru yang didorong oleh rangsangan seksual. Jika tidak dibimbing dengan tepat hal tersebut dapat membawa remaja terjerumus dalam hubungan seks pranikah dengan segala akibatnya

\section{Hubungan tempat sekolah dengan pengetahuan tentang kesehatan reproduksi remaja}

Dari hasil penelitian tentang hubungan tempat sekolah dengan pengetahuan, setelah dianalisis diperoleh nilai $\mathrm{p}=$ 0.000, dan nilaiartinya menunjukkan bahwa ada hubungan bermakna antara tempat sekolah dengan pengetahuan tentang kesehatan reproduksi remaja. Dan dari analisis lanjut diperoleh nilai $\mathrm{OR}=4.510$ (CI.2.660-7.647) artinya peluang SMA negeri mempunyai pengetahuan yang lebih baik sebenarnya mencapai 4.5 kali dibandingkan dengan siswa SMA di pondok pesantren. Penelitian yang sama mengenai perbandingan pengetahuan siswa SMA negeri dan swasta yang dilakukan oleh Aliyanto (2003) mengemukakan bahwa ada perbedaan bermakna pengetahuan remaja SMA negeri dan swasta dalam hal pngetahuan tentang kesehatan reproduksi remaja P.value $<0.05$ dan OR (3.74).

Informasi seks dari teman, film atau buku yang hanya setengahsetengah tanpa pengarahan, mudah menjerumuskan. Menurut Dr.Paat (2006), pendidikan seks pasif , karena tanpa komunikasi dua arah semacam itu sudah bisa mempengaruhi sikap dan perilaku seseorang, "Dalam pendidikan seks anak tidak cukup hanya melihat dan mendengar sekali dua kali, tetapi harus dilakukan secara bertahap dan berkelanjutan," katanya. Sebab itu pendidikan seks hendaknya menjadi bagian penting dalam pendidikan disekolah. Orang tua atau pendidik wajib meluruskan informasi yang tidak benar disertai penjelasan risiko perilaku seks yang salah

\section{Hubungan umur dengan pengetahuan tentang kesehatan reproduksi remaja.}

Hasil penelitian menunjukkan bahwa rata-rata umur responden adalah 16.75 dengan Standar Deviasi 0.725, minimum 15 tahun, dan maksimum 19 tahun. Pada tabel 5.14 di jelaskan bahwa responden yang berpengetahuan kurang baik terbanyak berumur samadenganataulebih dari 17 tahun $(83,3 \%), \quad$ sedangkan yang 
berpengetahuan baik hanya $16,7 \%$. Sedangkan umur dibawah 17 tahun yang berpengetahuan kurang baik (63\%), dan yang berpengetahuan baik hanya $(37 \%)$.

Secara psikologis masa remaja adalah usia dimana individu berintegrasi dengan masyarakat dewasa, usia dimana anak tidak lagi merasa dibawah tingkat orang-orang yang lebih tua melainkan berada dalam tingkatan yang sama. Menurut hukum di Amerika Serikat saat ini individu dianggap telah dewasa apabila telah mencapai usia 18 tahun. Awal masa remaja berlangsung kira-kira dari tiga belas tahun sampai dengan 16 tahun, dan akhir masa remaja bermula dari usia 16 tahun atau 17 tahun sampai dengan 18 tahun, yaitu usia matang secara hukum.

Dari hasil uji statistik diperoleh P.Value $<0.05$ yaitu 0.003 berarti ada hubungan bermakna antara umur dan pengetahuan tentang kesehatan reproduksi remaja. Dari hasil analisis juga diperoleh nilai $\mathrm{OR}=2,937$, artinya responden yang berusia $<17$ tahun berpeluang 2,9 lebih tinggi untuk memiliki pengetahuan yang baik tentang kesehatan reproduksi remaja dibandingkan responden yang berusia dibawah $\geq 17$ tahun
5.Hubungan jenis kelamin dengan pengetahuan tentang kesehatan reproduksi remaja

Hasilpenelitian menunjukkan bahwa responden yang memiliki pengetahuan yang kurang baik proporsinyalebih tinggi pada mereka yang berjenis kelamin laki-laki $(67,9 \%)$ dibandingkan yang berjenis kelamin perempuan (59\%). Hal ini sesuai dengan beberapa hasil penelitian sebelumnya mengenai pengetahuan remaja tentang risiko menjadi hamil hanya dengan sekali melakukan hubungan seksual lebih tinggi wanita dibanding pria, yaitu pria 50\% dibanding wanita 46\% (SDKI 20022003). Pada penelitian ini setelah diuji secara statistik, diperoleh P.value = $0,122(p>0.05)$ yang berarti bahwa secara statistik tidak ada hubungan yang bermakna antara jenis kelamin dengan pengetahuan tentang kesehatan reproduksi remaja. Pada analisis lebih lanjut diperoleh hasil bahwa P-value < $0.05(\mathrm{P}=0.039)$ artinya jenis kelamin juga memberi pengaruh positip teradap pengetahuan mengenai kesehatan reproduksi remaja

\section{Hubungan tempat tinggal dengan pengetahuan tentang kesehatan reproduksi remaja}

Hasil penelitian menunjukkan bahwa responden yang memiliki pengetahuan yang kurang baik 
proporsinya lebih tinggi pada mereka yang bertempat tinggal tidak bersama orang tua $(80,9 \%)$ dibandingkan yang bertempat tinggal bersama orang tua $(57.8 \%)$. Hasil analisis statistik diperoleh P.value $=0,000 \quad(p<0.05)$ yang berarti bahwa secara statistik ada hubungan yang bermakna antara tempat tinggal responden dengan pengetahuan tentang kesehatan reproduksi remaja. Hasil analisis juga diperoleh nilai OR $=3.096$, artinya responden yang tinggal bersama orang tua mempunyai peluang 3,096 kali lebih tinggi untuk memiliki pengetahuan yang baik tentang kesehatan reproduksi remaja dibandingkan responden yang tidak tinggal bersama orang tua.

Para remaja yang tidak tinggal bersama orang tua berisiko terpapar pengaruh lingkungan yang tidak sehat, termasuk penyalahgunaan obat, minuman beralkohol, tindakan kriminilitas, serta prostitusi (Iskandar 1997)

Keluarga merupakan lingkungan pendidikan pertama dan utama bagi anak. Keluarga berfungsi sebagai "transmiter budaya atau mediator" sosial budaya bagi anak. Menurut Undang-undang No 2 tahun 1989 Bab IV pasal 10 ayat 4 " Pendidikan keluarga merupakan bagian dari jalur pendidikan luar sekolah yang diselenggarakan dalam keluarga dan memberikan keyakinan nilai agama, budaya, moral dan keterampilan". (Yusuf.2005 : 39).

\section{Hubungan pendidikan ibu dengan pengetahuan tentang kesehatan reproduksi remaja}

Hasil analisis menunjukkan bahwa responden yang memiliki pengetahuan yang kurang baik proporsinya lebih tinggi pada mereka yang pendidikan ibunya SLTP ke bawah $\quad(70,7 \%)$ dibandingkan responden dengan pendidikan ibunya SMA ke atas $(60.5 \%)$. Hasil analisis diperoleh P.value $=0,028 \quad(\mathrm{p}<0.05)$ yang berarti bahwa secara statistik ada hubungan yang bermakna antara pendidikan ibu dengan pengetahuan tentang kesehatan reproduksi remaja. Hasil analisis juga diperoleh nilai OR $=1,537$, artinya responden dengan pendidikan ibu SMA ke atas mempunyai peluang 1,5 kali lebih tinggi unruk memiliki pengetahuan yang baik tentang kesehatan reproduksi remaja dibandingkan responden dengan pendidikan SLTP ke bawah. Hal ini sesuai dengan hasil penelitian Makarao , (1997) diketahui remaja yang orangtuanya berpendidikan SMA keatas mempunyai pengetahuan lebih baik dibanding orang tua SLTP kebawah. 
8.Hubungan pemberian materi kesehatan reproduksi di sekolah dengan pengetahuan tentang kesehatan reproduksi remaja

Hasil penelitian menunjukkan bahwa responden yang memiliki pengetahuan yang kurang baik proporsinya lebih tinggi pada mereka yang kurang memperoleh materi kesehatan reproduksi di sekolah (83.5\%) dibandingkan mereka yang cukup memperoleh materi kesehatan reproduksi di sekolah ( $61.2 \%$ ). Hasil analisis diketahui $(\mathrm{p}<0.05)$ yang berarti bahwa secara statistik ada hubungan yang bermakna antara perolehan materi di sekolah dengan pengetahuan tentang kesehatan reproduksi remaja. Dari hasil analisis juga diperoleh nilai $\mathrm{OR}=3,206$, artinya responden yang pernah memperoleh materi kesehatan reproduksi cukup di sekolah mempunyai peluang 3,2 kali lebih tinggi untuk memiliki pengetahuan yang baik tentang kesehatan reproduksi remaja dibandingkan mereka yang kurang/tidak pernah memperoleh materi kesehatan reproduksi di sekolah.

Dari hasil pengkajian kuesioner diketahui pula bahwa sebagian besar responden mendapatkan materi kesehatan reproduksi melalui mata ajaran biologi. Dalam rangka membantu remaja mencapai tugas perkembangannya maka sekolah dapat memfasilitasi dalam hal pengajaran tentang kesehatan reproduksi misalnya melalui mata ajaran biologi, kesehatan dan olah raga, atau layanan bimbingan guru mata ajaran atau guru pembimbing dapat memberikan penjelasan tentang kesehatan reproduksi remaja. Salah satu factor yang sering dianggap menurunkan motivasi siswa motivasi untuk belajar adalah materi pelajaran dan guru. Mengenai materi pembelajaran yang sering dikeluhkan adalah membosankan, terlalu sulit dan tidak bermanfaat (Sarwono, 2007 :125).

\section{Hubungan sumber informasi utama dengan pengetahuan tentang kesehatan reproduksi remaja}

Hasil

penelitian

menggambarkan bahwa responden yang memiliki pengetahuan yang kurang baik proporsinya sedikit lebih tinggi pada mereka yang memiliki sumber informasi kesehatan reproduksi dari luar orang tua $(72,6 \%)$ dibandingkan responden yang memiliki sumber informasi dari orang tua danatau guru ( $65,6 \%)$. Hasil penelitian Farihah (2000) tentang faktor yang berhubungan dengan pengetahuan remaja SMUN di Serang menunjukkan ada hubungan antara sumber informasi utama dengan 
pengetahuan tentang kesehatan repoduksi remaja. Penelitian ini diperkuat dengan penelitian Alianto (2003) tentang perbandingan pengetahuan tentang kesehatan reproduksi remaja pada siswa SMA negeri dan swasta di Lampung mengemukakan bahwa sumber info utama guru sekolah menyebabkan 2.5 kali untuk tahu tentang organ reproduksi dan fungsinya (OR 2.5 ), orang tua atau saudara 2 kali untuk tahu tentang kesehatan reproduksi remaja 2 kali (2.0).

\section{Hubungan akses informasi melalui media dengan pengetahuan tentang kesehatan reproduksi remaja}

Hasil penelitian menunjukkan bahwa responden yang memiliki pengetahuan yang kurang baik proporsinya hampir sama antara responden yang memiliki media informasi melalui media elektronik dan media masa masing-masing $65.8 \%$ dan 62,9 Hasil analisis ( $\mathrm{p}>0.05)$ yang berarti bahwa secara statistik tidak ada hubungan yang bermakna antara media informasi kesehatan reproduksi dengan pengetahuan tentang kesehatan reproduksi remaja.

Menurut. (Risnayati ,2000) , sumber informasi utama kesehatan reproduksi remaja yang dominan adalah melalui media cetak dan menyebabkan perilaku berisiko (OR 2.84).Penelitian (Aliyanto, : 2003), menyatakan bahwa, sumber informasi melalui media cetak menyebabkan 4.3 kali untuk tahu tentang kesehatan reproduksi remaja (OR 4.3). Hasil penelitian ini kurang sependapat dengan pernyataan tersebut karena dari hasil penelitian ini menggambarkan bahwa pengaruh media cetak dan elektronik hampir sama dan tidak menunjukan perbedaan yang bermakna dalam mempengaruhi pengetahuan remaja dalam hal kesehatan reproduksi remaja. Kemajuan tehnologi menyebabkan para remaja dapat mengakses informasi dari berbagai media.

\section{Simpulan}

1 Hasil penelitian tentang hubungan tempat sekolah dengan pengetahuan tentang kesehatan reproduksi remaja pada pelajar SMA di kabupaten Lebak menggambarkan bahwa, proporsi pengetahuan tentang kesehatan reproduksi remaja pada pelajar SMA (Sekolah Lanjutan Tingkat Atas) sebagian besar berpengetahuan kurang baik, bila dilihat dari tempat sekolah diketahui bahwa proporsi pengetahuan remaja yang kurang baik lebih banyak 
ditemukan pada pelajar SMA di pondok pesantren

dibandingkan pada SMA negeri (57, $8 \%)$.

2 Penelitian ini membuktikan bahwa ada hubungan bermakna tempat sekolah dengan pengetahuan tentang kesehatan reproduksi remaja pada pelajar SMA di kabupaten Lebak. Dari analisis lanjut diketahui OR 4.510 (CI 2.660-7.647) artinya pelajar SMA negeri mempunyai pengetahuan baik sebesar 4.5 kali dibandingkan SMA dipondok pesantren.

3. Pengaruh variable kovariat (umur, umur menarche pertama/mimpi basah, jenis kelamin, pendidikan ibu, tempat tinggal, materi kesehatan reproduksi, sumber informasi utama kesehatan reproduksi remaja, dan akses informasi kesehatan reproduksi remaja melalui media) ikut memperkuat penelitian ini, dari beberapa variable yaitu variable umur, pendidikan ibu, tempat tinggal, materi KRR menunjukkan hubungan bermakna, pada analisis lanjut diketahui variable pendidikan ibu dan jenis kelamin merupakan factor confounding hubungan tempat sekolah dengan pengetahuan tentang kesehatan reproduksi remaja.

\section{Daftar Pustaka}

BKKBN dan UNFPA, edisi revisi (2006), Keluarga Berencana, Kesehatan Reproduksi, Gender dan

Pembangunan Kependudukan, BKKBN dan UNFA Jakarta: $337 \mathrm{hlm}$

DEPKES RI (2004), Pedoman Pelayanan Kesehatan Peduli Remaja di Puskesmas, DEPKES Republik Indonesia, Jakarta

Kesehatan Pelayanan Integratif diTingkat Pelayanan Dasar, DEPKES RI, Jakarta

Ketahui petugas kesehatan
tentang $:$ Kesehatan
Reproduksi, DEPKES RI,
Jakarta

(1993) Direktorat Jendral Pembinaan Kesehatan Masyarakat, Direktorat Bina Kesehatan Keluarga ${ }_{2}$ Kumpulan Materi kesehatan reproduksi remaja, DEPKES RI, Jakarta:119 hlm

Jendral Bina Kesehatan Masyarakat, Pelayanan Kesehatan Peduli Remaja Materi Pelatihan Bagi petugas Kesehatan, Direktorat Jendral Bina Kesehatan Masyarakat, Jakarta

DEPKES RI dan World Health Organization (1999), Materi IntiKesehatan Reproduksi Remaja, Departemen Kesehatan RI, Jakarta: 52 hlm 
DEPKES RI-UNICEF (2007),

Penilaian Cepat Terhadap

Pelayanan dan Persepsi

Masyarakat Tentang Kesehatan

Maternal dan Neonatal di

Kabupaten LebakProvinsi

Banten, DEPKES RI, Jakarta 